International Journal of Pure and Applied Mathematics

Volume 103 No. 1 2015, 123-132

ISSN: 1311-8080 (printed version); ISSN: 1314-3395 (on-line version)

url: http://www.ijpam.eu

doi: http://dx.doi.org/10.12732/ijpam.v103i1.10

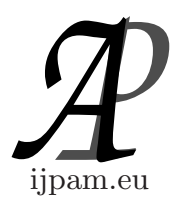

\title{
MODELLING STEAM GENERATOR SYSTEM OF PRESSURIZED WATER REACTOR USING FUZZY STATE SPACE
}

\author{
Azmirul Ashaari ${ }^{1}$, Tahir Ahmad ${ }^{2}$, Mustaffa Shamsuddin ${ }^{3}$, Nazira Omar ${ }^{4}$ \\ ${ }^{1,4}$ Department of Mathematical Science \\ Faculty of Science \\ Universiti Teknologi Malaysia \\ 81310, Skudai, Johor, MALAYSIA \\ ${ }^{2,3} \mathrm{Ibnu}$ Sina Institute for Fundamental Science Studies \\ Faculty of Science \\ Universiti Teknologi Malaysia \\ 81310, Skudai, Johor, MALAYSIA
}

\begin{abstract}
Steam generator is one of the components in pressurized water reactor (PWR) system. It is known as the bridge between the primary and secondary systems which is also famous as the place for phase changes from water into steam. The aim of this paper is to model and investigate the performance of steam generator using Fuzzy State Space Model (FSSM). The influence between input and output of the steam generator is established. The result from the model is then verified against published data.
\end{abstract}

AMS Subject Classification: 97M10, 93A30, 70G10

Key Words: power plant, pressurized water reactor, steam generator, fuzzy state space

Received: April 21, 2015

(c) 2015 Academic Publications, Ltd. url: www.acadpubl.eu

${ }^{\S}$ Correspondence author 


\section{Introduction}

In general, a model is developed to understand and describe a system. However, several rules must be met in order for a model to be valid. Robert et al. [1] presented a developed model of a nuclear power reactor where the transients situation is not considered. Pomerantz et al. [2] presented a theoretical model of a nuclear power reactor. Some systems are described verbally through vague, uncertain or inaccurate statements. F. High [3] stated that characterizing equations are generally a set of partial differential equations, with nonlinearity arising due to convection of momentum in the flow, variable properties and radioactive transport.

Approximation and idealization techniques are used to simplify these equations, resulting in algebraic and ordinary differential equations. In order to solve the problem of nonlinearity, fuzzy state space modelling method is used.

\section{Steam Generator}

Steam generator is used as a place to conduct heat transfer between two systems namely primary and secondary systems. The heat generated from a nuclear fission in the primary system is transmitted to a steam generator via moderator as shown in Fig.1. The phase change from water into steam is formed in the secondary system. Then the steam is transferred to the main turbine via the secondary system circuit where electricity is generated. Next, the steam is routed to the main condenser to remove excess heat from the steam, which allows the steam to condense. The water is then piped back to the steam generator for reuse. This process is repeated until the PWR reactor is shut down [4].

There are some assumptions are made in order to have a low order dynamic model of a steam generator as given in [5]:

1. The dynamics of the primary system of the steam generators is faster than secondary system in steam generator, therefore it is assumed in a quasi-steady state and conservation balances are not be constructed.

2. The dynamics of the secondary system in steam phase is also faster than secondary system in liquid phase for steam generator, therefore it is assumed to be equilibrium between the water and the steam phases.

3. The physical properties are assumed to be constant for the secondary system in steam generators. 


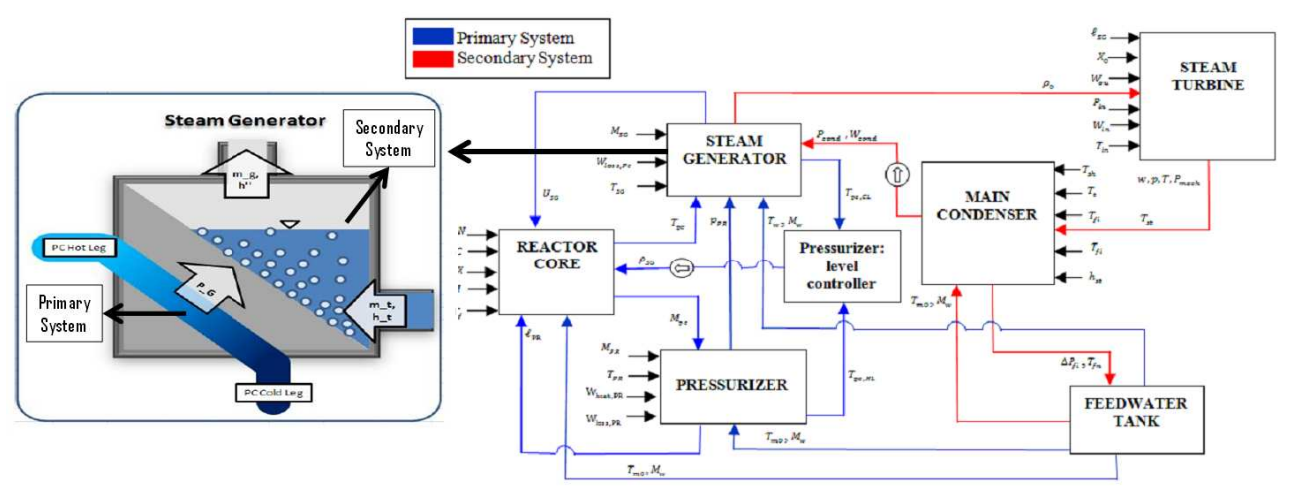

Figure 1: Steam Generator Model [5]

4. All the controllers on the secondary system including the water level and secondary steam pressure controller are assumed to be ideal.

All mass balance in a steam generator such as the moderator in the secondary system is simplified to an algebraic equation. The inlet secondary water mass flow rate $m_{S G, s w}$ and the outlet secondary steam mass flow rate $m_{S G, s s}$ are considered to be equal by the ideal of water level controller on the steam generators; i.e.

$$
m_{S G, s w}=m_{S G, s s}=m_{S G}
$$

The mass conservation for each of the balance volumes are as follows:

$$
\begin{gathered}
\frac{d M_{S G}}{d t}=m_{S G, \text { in }}-m_{S G, \text { out }} \\
\frac{d T_{S G}}{d t}=\left(C_{p, S G}^{L} m_{S G} T_{S G, S W}+C_{p, S G}^{v} m_{S G} T_{S G}-m_{S G} E_{\text {evap }, S G}\right. \\
\left.+K_{T, S g}\left(T_{P C}-T_{S G}\right)-W_{\text {loss }, P C}\right) / c_{p, S G}^{L} M_{S G}
\end{gathered}
$$

where $T_{S G}$ is the temperature, $c_{p, S G}^{L}$ is the water specific heat, $c_{p, S G}^{v}$ is the vapour specific heat, $T_{S G, S W}$ is the inlet temperature, $E_{\text {evap }, S G}$ is the evaporation energy, and $W_{\text {loss, } P C}$ is the heat loss. The state space for a steam generator 
is given as:

$$
\begin{array}{r}
\left(\begin{array}{c}
\frac{d M_{S G}}{d t} \\
\frac{d T_{S G}}{d t}
\end{array}\right)=\left(\begin{array}{cc}
\frac{m_{S G, \text { in }}}{M_{S G}} & \frac{-m_{S G, \text { out }}}{T_{S G}} \\
\frac{T_{S G, s w}}{M_{S G}}-\frac{\left(C_{p, S G}^{v} m_{S G} T_{S G}+E_{\text {evap }, S G}\right)}{C_{p, S G}^{L} M_{S G}} & \frac{-K_{T, S g}}{C_{p, S G}^{L} M_{S G}}
\end{array}\right) \\
\left(\begin{array}{c}
M_{S G} \\
T_{S G}
\end{array}\right)+\left(\begin{array}{cc}
0 & 0 \\
\frac{-K_{T, S g}}{C_{p, S G}^{L} M_{S G}} & \frac{-1}{C_{p, S G}^{L} M_{S G}}
\end{array}\right)\left(\begin{array}{c}
T_{P C} \\
W_{\text {loss }, P C}
\end{array}\right)
\end{array}
$$

The output is:

$$
\left(\begin{array}{c}
U_{S G} \\
p_{S G}
\end{array}\right)=\left(\begin{array}{cc}
C_{p, S G}^{L} T_{S G} & 0 \\
0 & p_{*}^{T}
\end{array}\right)\left(\begin{array}{c}
M_{S G} \\
T_{S G}
\end{array}\right)
$$

Here the general formula for thermodynamic potential or enthalpy $(\mathrm{H})$ of the system can be stated as follows $[6,7]$ :

$$
H=U+p V
$$

where $\mathrm{U}$ is denoted as the internal energy of system, $\mathrm{p}$ is denoted as the as product of pressure and V is denoted as the volume of the system. From (6), the internal energy formula can also be constructed as follows:

$$
U=H-p V
$$

The same concept is applied in steam generator where $U$ is denoted as internal energy, $\mathrm{p}$ is denoted as a product of pressure and $\mathrm{V}$ is denoted as volume of a steam generator. In order for internal energy value to be higher, the pressure or volume value needs to be lower. Therefore, the internal energy is increased or decreased whenever the pressure is increased or decreased within the system of steam generator.

\section{Fuzzy State Space}

Zadeh [8] introduced the term fuzzy set as a general model of uncertainty encountered in science and engineering systems. A. Kaufman [9] stated that modelling of uncertain parameters on a system can be controlled and presented by fuzzy numbers. Hence in 2004, a Fuzzy State Space Modelling (FSSM) method to model a multivariable dynamic systems is presented by Razidah et 
al. [10].The definition of the FSSM of a multivariable dynamic system [10] is given as follows:

$$
\begin{array}{r}
S g F: x^{\prime}(t)=A x(t)+B u(t) \\
y(t)(t)=C x(t)
\end{array}
$$

where $\mathrm{u}$ denotes the fuzzified input vector $\left[u_{1}, u_{2},, u_{n}\right]^{T}$ and $\mathrm{y}$ denotes the fuzzified output vector $\left[y_{1}, y_{2}, y_{m}\right]^{T}$ with initial conditions as $t_{0}=0$ and $x_{0}=x\left(t_{0}\right)=0$. The elements of state matrix , input matrix and output matrix are known to a specified accuracy.

A steam generator contains two inputs and two outputs known as multipleinput multiple-output (MIMO) model. However, a MIMO model can be split into m equivalent MISO models with all of the $n$ input parameters of the system but only one of the m output parameters being subject to a fuzzy model. Thus, a steam generator with two inputs and two outputs can be reduced to a fuzzy MISO models with two inputs and one output. The algorithm to determine a fuzzy set $F_{S a}$ was introduced by Razidah et al. [11]. The final steps of the algorithm are determined by applying the Modified Optimized Defuzzified Value Theorem as follows:

Theorem 1. Modified Optimized Defuzzified Value [11] Let $S_{a}: R^{n} \rightarrow R$ where $S_{a}$ is a performance parameter based on the Fuzzy State Space Model. If $S_{a}^{*}=r_{j}^{*} \max r_{j}$ such that $\mu\left(r_{j}^{*}\right)=f^{*}$ for all $\left(r_{j}, f^{*}\right) \in F_{\text {ind }}$, then $r_{j}^{*}=S_{a}^{*}=$ $\max \left[S_{a}\left(a_{1}^{*}, a_{2}^{*}, a_{3}^{*}, a_{n}^{*}\right)\right]$ where $\mu\left(a_{p}^{*}\right)=f^{*}$.

\section{Result and Discussion}

The simulation of the PWR is conducted by using data obtained from [12]. The equation of state space for the steam generator is fuzzified where fuzzy inputs values are shown in Fig.2. Meanwhile, the a-cuts for fuzzy inputs value with step size of 0.2 are shown in Table 1 . The output equations are given as follows:

$$
\begin{gathered}
U_{S} G=3.70126\left(T_{P C}+W_{\text {loss }, P C}\right) \\
p_{S} G=1.95 \times 10^{-7}\left(T_{P C}+W_{\text {loss }, P C}\right)
\end{gathered}
$$

The desired value and its domain for fuzzy outputs preferred steam generator are shown in Table 2. On the other hand, Table 3 shows the domain and the desired value for fuzzy performance parameter of the steam generator that were 


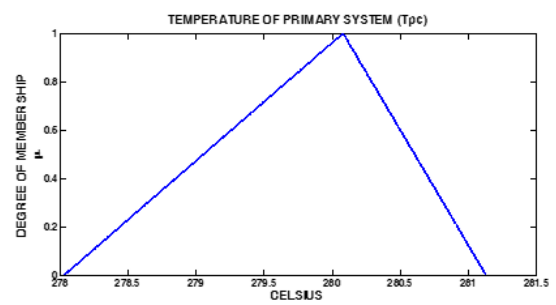

(a)

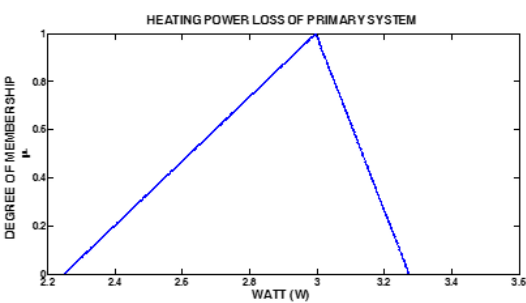

(b)

Figure 2: Fuzzy Input of Steam Generator

Table 1: Fuzzy Input $\alpha$-cuts

\begin{tabular}{|c|c|c|c|c|c|c|c|c|c|c|c|}
\hline $\begin{array}{l}\text { Input } \\
\text { Pa- } \\
\text { rame- } \\
\text { ter }\end{array}$ & 0.0 & 0.2 & & 0.4 & & 0.6 & & 0.8 & & 1.0 & \\
\hline$T_{P C}$ & $\begin{array}{l}278.03- \\
281.13\end{array}$ & $\begin{array}{l}278.4 \\
280.9\end{array}$ & - & $\begin{array}{l}278.8 \\
280.7\end{array}$ & - & $\begin{array}{l}279.3 \\
280.5\end{array}$ & & $\begin{array}{l}279.7 \\
280.3\end{array}$ & - & $\begin{array}{l}280.08 \\
280.08\end{array}$ & \\
\hline$W_{l o s}$ & $\begin{array}{l}2.2469 \times \\
10^{8}- \\
3.2773 \times \\
10^{8}\end{array}$ & $\begin{array}{l}2.397 \\
10^{8} \\
3.218 \\
10^{8}\end{array}$ & $\begin{array}{l}\times \\
- \\
\times\end{array}$ & $\begin{array}{l}2.547 \\
10^{8} \\
3.162 \\
10^{8}\end{array}$ & $\begin{array}{l}x \\
- \\
x\end{array}$ & $\begin{array}{l}2.696 \\
10^{8} \\
3.107 \\
10^{8}\end{array}$ & $\begin{array}{l}x \\
- \\
\times\end{array}$ & $\begin{array}{l}2.847 \\
10^{8} \\
3.051 \\
10^{8}\end{array}$ & $\begin{array}{l}\times \\
- \\
\times\end{array}$ & $\begin{array}{l}2.996 \\
10^{8} \\
2.996 \\
10^{8}\end{array}$ & $\begin{array}{l}x \\
- \\
x\end{array}$ \\
\hline
\end{tabular}

calculated using (8) and (9). Fig. 3 shows the intersection between the fuzzy output preferred and fuzzy performance parameters of the steam generator.

The intersection between both graphs are determined in order to obtain the fuzzy optimal value $\left(f^{*}\right)$. The fuzzy value of $f^{*}$ is used in finding optimal input parameter by using Modified Optimized Defuzzified Value Theorem. Table 4 shows the optimal input for $T_{P C}$ is $279.5^{0} \mathrm{C}$, and $W_{\text {loss, } P R}$ is $2.78 \times 10^{8} \mathrm{~kJ} / \mathrm{s}$ with the percentage errors of 0.21 and 7.21 respectively. The optimal output value are $U_{S G}=11.32 \times 10^{8} J$ and $p_{S G}=44.50$ bar with percentage errors 1.92 and 0.63 respectively as shown in Table 5 .

The percentage errors are small as given in Table 5. Next, the optimal input in Table 4 is determined using Matlab Simulink as shown in Fig 4. Equations (4) and (5) are used for simulation from 0.1 until 500 seconds. The input data are manipulated to be either decreased or increased in order to define the pattern of output for steam generator as given in Fig. 5 and 6. 
Table 2: Fuzzy Output Preferred Parameter

\begin{tabular}{|l|l|l|}
\hline & Domain & Desire Value \\
\hline$U_{S G}$ & $10.589 \times 10^{8}-$ & $11.542 \times 10^{8}$ \\
& $13.351 \times 10^{8}$ & \\
\hline$p_{S G}$ & $43.4-45.3$ & 44.5 \\
\hline
\end{tabular}

Table 3: Fuzzy Performance Parameter

\begin{tabular}{|l|l|l|}
\hline & Domain & Desire Value \\
\hline$U_{S G}$ & $8.316 \times 10^{8}-12.115 \times$ & $11.089 \times 10^{8}$ \\
& $10^{8}$ & \\
\hline$p_{S G}$ & $43.80-63.83$ & 58.42 \\
\hline
\end{tabular}

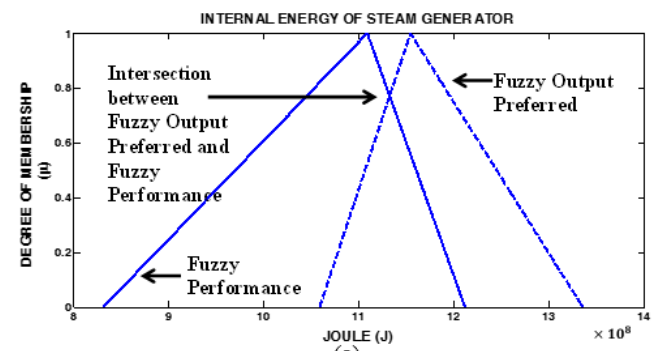

(a)

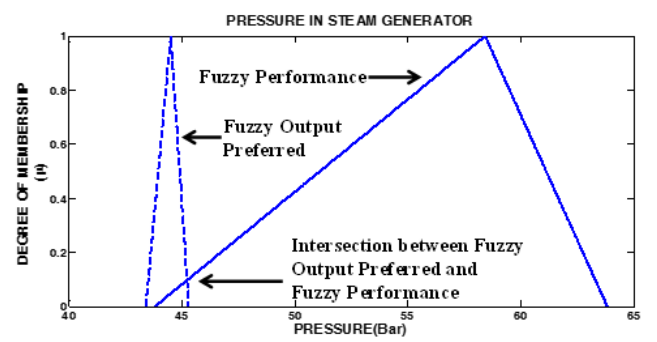

(b)

Figure 3: Intersection of fuzzy output performance and fuzzy preferred output for: a) Internal Energy of Steam Generator b)Pressure of Steam Generator

Figs. 5 and 6 show that internal energy and pressure in steam generator are in agreement with the assumptions (see section steam generator) that are made for the steam generator. If the internal energy increased, then the pressure is decreased. On the other hand, if the internal energy decreased, then the pressure is increased. Fig.5 shows that when the input for $T_{P C}$ and $W_{l o s s, P C}$ are increased, the internal energy is decreased while the pressure in steam generator is increased. It is caused by the increasing of $T_{P C}$. Hence, the level of water is increasing and the pressure is also increasing. The internal energy of the steam generator is decreasing. When the input for $T_{P C}$ and $W_{\text {loss }, P C}$ are decreasing, the internal energy is increasing and pressure is decreasing. It is due to the 


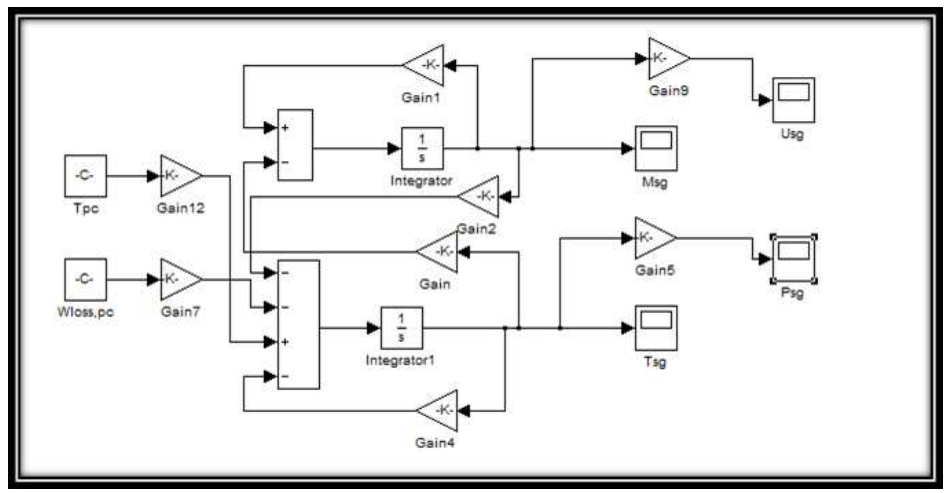

Figure 4: Modeling Fuzzy State Space of Steam Generator

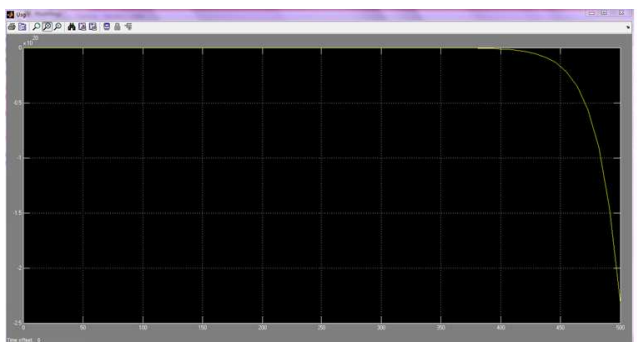

(a)

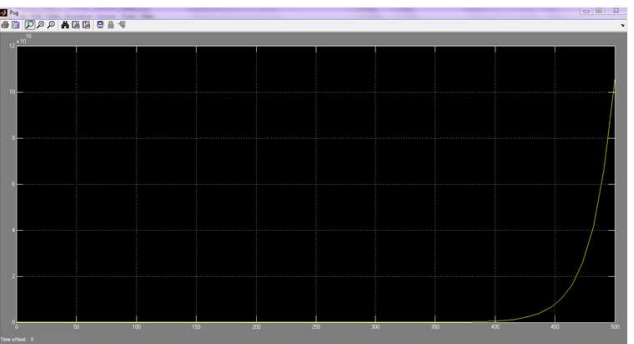

(b)

Figure 5: Graph of output when $T_{P C}$ and $W_{\text {loss,PC }}$ are increased for: a) Internal Energy of Steam Generator b) Pressure of Steam Generator

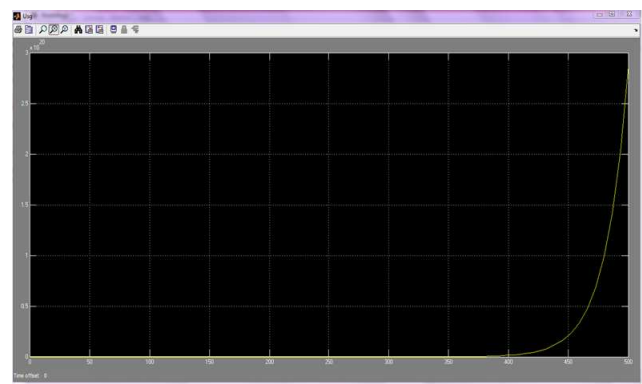

(a)

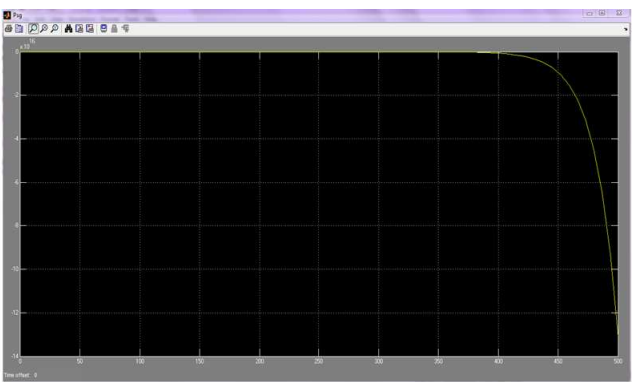

(b)

Figure 6: Graph of output when $T_{P C}$ and $W_{\text {loss,PC }}$ are decreased for: a) Internal Energy of Steam Generator b) Pressure of Steam Generator 
Table 4: Optimal Value for Input Parameter of Steam Generator

\begin{tabular}{|l|l|l|l|}
\hline $\begin{array}{l}\text { Input Pa- } \\
\text { rameter }\end{array}$ & Calculated & Preferred & $\begin{array}{l}\text { Percentage } \\
\text { Error (\%) }\end{array}$ \\
\hline$T_{P C}$ & 279.5 & 280.8 & 0.21 \\
\hline$W_{\text {loss }, P C}$ & $2.78 \times 10^{8}$ & $2.996 \times 10^{8}$ & 7.21 \\
\hline
\end{tabular}

Table 5: Optimal Value for Output of Steam Generator

\begin{tabular}{|l|l|l|l|}
\hline $\begin{array}{l}\text { Output Pa- } \\
\text { rameter }\end{array}$ & Calculated & Preferred & $\begin{array}{l}\text { Percentage } \\
\text { Error (\%) }\end{array}$ \\
\hline$U_{S G}$ & $11.32 \times 10^{8}$ & $11.542 \times 10^{8}$ & 1.92 \\
\hline$p_{S G}$ & 44.22 & 44.50 & 0.63 \\
\hline
\end{tabular}

increasing of heat lost, $W_{\text {loss }, P R}$ whereby reactor coolant temperatures start to decrease. Therefore, the water level decrease and the pressure decrease. Hence the internal energy is increased.

\section{Conclusion}

The fuzzy state space modelling for a steam generator in pressurized water reactor is obtained. The results from fuzzy state space algorithm show that the percentage error for the input and output are small. The simulation results show that if internal energy is increased, the pressure is decreased. On the other hand, if the internal energy decreased then the pressure is increased..

\section{Acknowledgments}

This work has been supported by Ibnu Sina Institute, MyBrain15 scholarship from Ministry of High Education Malaysia and University Teknologi Malaysia.

\section{References}

[1] Edwards Robert, M., Lee Kwang, Y., Shultz, M.A., State feedback assisted classical control: an incremental approach to control modernization of ex- 
isting and future nuclear reactors and power plants, Nuclear technology, 92, No.2(1990), 167-185.

[2] Pomerantz, M. E., Calabrese, C. R., and Grant, C., Nuclear reactor power and flux distribution fitting from a diffusion theory model and experimental data, Annals of Nuclear Energy, 29, No.9 (2002), 1073-1083.

[3] High, F., Order, L. and Reasons, I., Control-oriented Model Reduction and Controller, Control-oriented Model Reduction and Controller, Springer, London (2000).

[4] Geoffrey F. Hewitt and John G. Collier., Introduction to Nuclear Power. 2nd edition, Taylor \& Francis, United States of America (2000).

[5] Gbor, Attila and Sonnevend, Ilona and Bartha, Tams, Control-oriented modelling of the primary circuit and its controllers of a PWR nuclear power plant. In 9th European Workshop on Advanced Control and Diagnosis, Budapest, Magyarorszg, November 1718 (2011).

[6] Guggenheim E.A., Thermodynamics, North-Holland Publishing Company, Amsterdam (1959).

[7] Zumdahl, Steven S., Thermochemistry Chemistry,Charles Hartford, United States (2008).

[8] Zadeh, L.A., Fuzzy sets, Information and Control, 8, No.3 (1965), 338-353.

[9] Kaufman,A. and Gupta, M.M., Introduction to Fuzzy Arithmetic: Theory and Application, Van Norstrand Reinhold, New York(1985).

[10] R. Ismail, T. Ahmad, S. Ahmad and R.S Ahmad., On The Properties of Multi-Connected System Of Fuzzy State Space Model, Proc. The 2nd. International Conference on Research and Education in Mathematics (ICREM 2), Institute of Mathematical Research, Universiti Putra Malaysia, 43400 Serdang (2005), May 25-27.

[11] Ismail, Razidah, and Noor Ainy Harish, A Fuzzy Algorithm for Parameter Estimation of a Superheater System, Latest Advances in Information Science, Circuits and Systems, (2008), 55-61.

[12] Fazekas, Cs, Gbor Szederknyi, and K. M. Hangos., A simple dynamic model of the primary circuit in VVER plants for controller design purposes, Nuclear Engineering and Design, 237, No. 10 (2007), 1071-1087. 